\title{
DE PATRONA DE LA MONARQUÍA A PATRONA DE LA NACIÓN. LA INMACULADA CONCEPCIÓN ENTRE PORTUGAL Y ESPAÑA (1800-1854)
}

\section{From patroness of the Monarchy to patroness of the nation. The Immaculate Conception between Portugal and Spain (1800-1854)}

\author{
DAVID MARTÍNEZ VILCHES \\ Universidad Complutense de Madrid \\ damart06@ucm.es
}

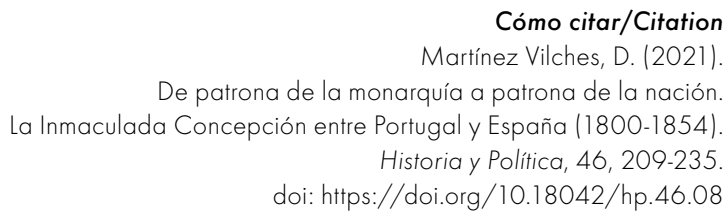

(Recepción: 04/06/2019; evaluación: 27/07/2019; aceptación: 16/01/2020; publicación: 30/11/2021)

Resumen

Este artículo analiza la transición de devoción dinástica a devoción nacional de la Inmaculada Concepción en España y Portugal durante la primera mitad del siglo XIX. Esta reformulación simbólica constituyó una vía de politización y nacionalización a través de la religión en ambos países ibéricos. El estudio de los discursos religiosos nos lleva a considerar que, a pesar de las contradicciones entre liberales y católicos, ni unos ni otros renunciaron a la centralidad del componente religioso heredado a la hora de construir la nación tras la caída del Antiguo Régimen.

\section{Palabras clave}

Inmaculada Concepción; nacionalización; politización; catolicismo; liberalismo. 


\begin{abstract}
This article analyses the transition of the Immaculate Conception from dynastic devotion to national devotion in Spain and Portugal during the first half of the 19th century. This symbolic reformulation was a way of nation-building and politicisation through religion in both Iberian countries. The study of religious discourses leads us to consider that, in spite of the contradictions between liberals and catholics, neither of them renounced the centrality of the inherited religious component at the time of building the nation after the fall of the Ancien Régime.
\end{abstract}

\title{
Keywords
}

Immaculate Conception; nation-building; politicisation; catholicism; liberalism. 
I. INTRODUCCIÓN. II. DE PATRONA DE LA MONARQUÍA FIDELÍSIMA A PATRONA DE LA NACIÓN FIDELÍSIMA. III. DE PATRONA UNIVERSAL DE LOS REINOS DE ESPAÑA E INDIAS A PATRONA DE ESPAÑA. IV. CONCLUSIONES. BIBLIOGRAFÍA.

\section{INTRODUCCIÓN}

"No hizo lo mismo con todas las naciones». Con este versículo del Libro de los Salmos $(147,20)$ se ha invocado en numerosas ocasiones la predilección divina de la Virgen María por una determinada nación. Así, por ejemplo, el polígrafo católico Basilio Sebastián Castellanos de Losada señalaba que a ningún otro país como a España se aplicaba con tanta propiedad las palabras del salmista, pues ella «es hija predilecta de la religión del Crucificado». Y en nota añadía la causa última de esta trascendente identificación entre la nación española y el catolicismo: Espańa tenía "por escudo y defensa de su fe a la Virgen Inmaculada», el «escudo salvador de nuestra nación»". Pero lo cierto es que esta pretensión de monopolizar el favor de la Virgen no era privativa de los españoles. También por entonces los católicos portugueses aclamaban a la Virgen como su particular protectora, e igualmente lo hacían en su advocación como Inmaculada, la Virgen de la Concepción. Su historia como Padroeira de Portugal se remontaba a los tiempos de lucha frente a la Monarquía Hispánica, cuando Juan IV la eligió como patrona por «os conhecidos beneficios que a naçáo portugueza recebu sempre do Patrocinio da Santisima Virgem da Conceição em todas as épocas arriscadas da monarchia» ${ }^{3}$.

Las siguientes páginas proponen un análisis comparativo en los países ibéricos del proceso de politización y nacionalización de este misterio mariano en su transición de advocación dinástica a devoción nacional en la primera mitad del siglo XIx. Los fenómenos devocionales de esta centuria constituyen

1 Este trabajo se integra dentro del proyecto de investigación «Cultura del honor, política y esfera pública en la España liberal (1833-1890)», financiado por el Ministerio de Ciencia, Innovación y Universidades (PGC2018-093698-B-I00), y en el Programa de Formación del Profesorado del Universitario (FPU 17/00545). El autor agradece a la profesora Raquel Sánchez las sugerencias realizadas sobre el manuscrito original.

2 Castellanos de Losada (1855): 667.

3 Fernandes (1865): 14. 
un objeto de estudio explorado cada vez más por la historiografía contemporaneísta. Este campo, que anteriormente no dejaba de ser un ámbito reservado a estudiosos eclesiásticos, se ha ido abriendo a nuevas miradas para considerar cómo, más allá de los moldes institucionales de la Iglesia, los discursos y las prácticas religiosas se plantearon a modo de respuesta ante el arranque de la modernidad y las necesidades simbólicas que con ella surgían en el campo religioso. En este sentido, se ha subrayado la intensificación de algunos cultos, como el Sagrado Corazón de Jesús, que respondían a las mutaciones sobrevenidas tras el impacto de la Revolución ${ }^{4}$. Y también las devociones marianas - la Inmaculada especialmente - han sido objeto de atención por su virtualidad a la hora de proyectar desde la dimensión trascendente de lo sagrado contenidos políticos, nacionales, sociales o de género en las sociedades modernas5.

El caso que aquí nos ocupa nos lleva a considerar las posibilidades del uso de lo religioso como elemento de nacionalización en el siglo xix. La religión, que había sido uno de los pilares del Antiguo Régimen, se convirtió en el nuevo contexto liberal en una fuente inagotable de recursos para extender la idea de nación entre los ciudadanos ${ }^{6}$. Así pues, al haber constituido un elemento clave de comunión de todos los súbditos de una monarquía (como afirmaba el principio de "Cuius regio, eius religio»), la religión era un referente de identidades y lealtades susceptibles de ser aplicadas a la nación, un fenómeno que afectó de manera intensa a las devociones religiosas como la de nuestro objeto de estudio. Tanto en Espańa como en Portugal, la Inmaculada había sido una devoción estrechamente vinculada a la monarquía - y especialmente esgrimida en el contexto de la Contrarreforma católica-, que acabó resimbolizada en términos nacionales en el siglo xix. Su patronazgo se extendió desde el reino y la monarquía al conjunto de la nación, proyectándose en una nueva escala que convertía a sus protegidos en un sujeto político nacional.

Además, en ese proceso de apropiación y resignificación la Inmaculada se revistió no solo de caracteres nacionales, sino también políticos. Y ello en un momento de tensión entre la Iglesia y el liberalismo en toda la Europa

4 Kselman (1983); Cattaneo (1995); Rodríguez (1998); Jonas (2000); Broers (2002), y Serrano et al. $(2014,2018)$.

5 Coreth (2004); Zimdars-Swatz (1992); Blackbourn (1993); Fattorini (1997); Harris (1999); Angelier y Langlois (2000); Béthouart y Lottin (2005); Langlois (2005); Kaufman (2005); Boyd (2007); Menozzi (2014); Ramón Solans (2014); Mínguez Blasco (2016); Di Stefano y Ramón Solans (2016), y Martínez Vilches (2017, 2019, 2020a, 2020b).

6 Haupt (2008) y Haupt y Langewiesche (2001, 2010). 
católica y, por tanto, también en la península ibérica. Es en este contexto - y no casualmente - cuando se produjo la definición dogmática de la Inmaculada Concepción. Anteriormente, la creencia de que María había sido preservada del pecado original había constituido una opinión muy piadosa, pero que no todos compartían en el seno de la Iglesia. Fue Pío IX quien tomó la iniciativa de elevarla a categoría de dogma de fe. Desde su exilio en Gaeta, a donde le había llevado a refugiarse la Revolución de 1848, el papa inició el proceso de proclamación dogmática con la encíclica Ubi primum de 2 de febrero de 1849. En ella se solicitaba la opinión de los obispos, en su inmensa mayoría favorables. De vuelta en Roma, Pío IX puso en marcha la definición dogmática, que sería dada a conocer en la bula Ineffabilis Deus el 8 de diciembre de 1854. Si bien no contenía un compendio de errores modernos, como se barajó en un primer momento, el contenido de la bula distaba mucho de ser políticamente aséptico. Ante todo, suponía un reforzamiento de la autoridad del papa en el seno de la Iglesia. Pero, además, en su vertiente doctrinal el dogma de la Inmaculada reafirmaba las creencias del pecado original (del que María fue preservada) y de la divinidad de Jesucristo (en la que se fundamentaba ese privilegio), oponiéndose a las ideas del racionalismo y del indiferentismo religioso. No en vano la Inmaculada era representada pisando la serpiente, lo que reactualizaba la profecía que Dios dirigió al reptil tras incitar a Eva a pecar: "Pondré enemistad entre ti y la mujer, y entre su simiente y la simiente suya; esta te herirá en la cabeza, y tú la herirás en el talón» (Génesis $3,15)$. Y en un momento en el que la Iglesia se sentía acosada por la revolución y la modernidad, una Inmaculada triunfante sobre el mal no solo era una imagen reconfortante, sino también movilizadora entre las propias filas ${ }^{7}$.

Nuestro análisis examina los discursos religiosos sobre la Inmaculada Concepción en España y Portugal y su evolución de devoción dinástica a devoción nacional en el siglo xIx. Con ello pretendemos poner de relieve una misma dinámica religiosa en ambos países ibéricos en el tránsito del Antiguo Régimen a la época del liberalismo. Su interés estriba en constatar cómo, a pesar de las contradicciones entre liberales y católicos, ni unos ni otros renunciaron a la centralidad del componente religioso heredado a la hora de construir la nación tras la caída del Antiguo Régimen. Y ello a pesar de que constituyese un elemento polémico, no solo entre el liberalismo y las alternativas legitimistas (miguelismo en Portugal y carlismo en España), sino entre las distintas sensibilidades dentro del espectro ideológico liberal y en el propio seno de la Iglesia. Así pues, este tipo de análisis nos confronta con una visión más poliédrica de las relaciones entre liberalismo y catolicismo.

7 Cecchin (2004); Langlois (2005), y Menozzi (2014). 


\section{DE PATRONA DE LA MONARQUÍA FIDELÍSIMA A PATRONA DE LA NACIÓN FIDELÍSIMA}

Ya desde el siglo XIII constan evidencias documentales de la celebración de la fiesta de la Concepción en Portugal, de la misma manera que se celebraba en otros países, si bien la creencia de que la Virgen fue concebida sin pecado original no era compartida por todos los teólogos ${ }^{8}$. Asimismo, desde la Baja Edad Media existía una larga tradición de invocación de María como defensora de la monarquía portuguesa, que tenía sus orígenes en el enfrentamiento entre Castilla y Portugal que acabó dirimiéndose en la victoria lusa de Aljubarrota (1385), atribuida al favor de la Virgen hacia los portugueses 9 . No obstante, el patronazgo de María sobre Portugal, en su específica advocación como Inmaculada Concepción, se remonta al 6 de diciembre de 1644, cuando Juan IV proclamó a la Inmaculada patrona de Portugal, lo que sancionaron las Cortes el 25 de marzo de 1646. Ese mismo día, el monarca juraba en su Capilla Real defender la creencia de la concepción de María sin mancha de pecado, y prometía ofrecer todos los años a modo de vasallaje cincuenta cruzados de oro a la Santa Casa da Conceiçáo de Vila Viçosa, por ser el primer templo creado en Portugal bajo esta advocación. Claro está que el duque de Braganza pretendía la utilización de la devoción mariana como un elemento de legitimación para hacer valer sus derechos al trono portugués frente a la monarquía hispánica. No en vano, el voto que hacía Juan IV a la Inmaculada como patrona de Portugal recordaba el vasallaje de Alfonso Enríquez hacia Santa María de Claraval, trazando una línea de continuidad entre el fundador del reino y él ${ }^{10}$. En todo caso, patrona de Portugal significaba patrona de la monarquía portuguesa restaurada en la dinastía de los Braganza, y no una apelación a ningún tipo de identidad nacional. Era el monarca quien había declarado su patronazgo y las Cortes del reino lo sancionaban; todo quedaba, pues, dentro del sistema de lealtades del Antiguo Régimen.

Pasados los años, ya en el siglo xIx, el uso simbólico y político de la Inmaculada como patrona de Portugal tuvo un hito fundamental en el Trienio Vintista, entre 1820 y 1823 . Este breve periodo de tiempo en el que el liberalismo intentó la implantación de un sistema constitucional se caracterizó por un fuerte enfrentamiento entre el Estado liberal y una Iglesia reticente a cualquier tipo de reforma ${ }^{11}$. Por su parte, los sectores absolutistas vieron en el segundo hijo

\footnotetext{
Faria (1984).

Costa (1957).

Faria (2010): 61-61.

1 Faria (2006).
} 
de Juan VI, el príncipe Miguel, la posibilidad de una involución política que resucitase la alianza del trono y el altar. Y todo ello en un contexto internacional de vigencia del sistema de la Restauración, renovado en los congresos de Troppau (1820), Laibach (1821) y Verona (1822). En mayo de 1822, cuando las Cortes ultimaban la Constitución, unos niños que jugaban en las orillas del río Jamor en Carnaxide, cerca de Lisboa, se internaron en una cueva en la que, a los pocos días, apareció una imagen de la Virgen de la Concepción, enseguida apelada «de la Rocha» por el lugar. En aquel contexto de tensión política, el descubrimiento de una imagen de la Virgen, precisamente en su advocación como padroeira del reino, adquirió tintes apocalípticos y proféticos frente al sistema liberal. La aparición sería una advertencia a los portugueses de los derroteros que estaba tomando el país en esos momentos dramáticos. «Sempre a grandes males o Ceo acode com grandes remedios», escribiría frei Claudio da Conceição, futuro cronista regio del rey Miguel I. «Eu náo vejo maior mal que a falta de Religião nos Catholicos $»^{12}$.

Para hacer frente a la apropiación simbólica reaccionaria de la aparición ocurrida en Carnaxide, el Gobierno liberal ordenó recoger la imagen y llevarla a la catedral de Santa María Mayor. El traslado se llevó a cabo el día 5 de agosto y para verificarlo se necesitó la intervención de un regimiento. Una vez en Lisboa, el sermón de bienvenida a la imagen correría a cargo de Marcos Pinto Soares Vaz Preto. Más conocido como el padre Marcos, se trataba de un religioso de hondas convicciones liberales y masón, además de amigo personal del ministro de Negocios de Justicia, José da Silva Carvalho ${ }^{13}$. Su elección aseguraba al Gobierno un contenido favorable al régimen constitucional en el sermón, en el que el padre Marcos disertó en torno al papel de las imágenes religiosas. Insistía en que estas eran objeto de culto porque hacían referencia a las realidades sublimes de la religión. Así, todas las imágenes de María debían ser veneradas por igual, ya que todas representaban a la madre de Dios. La Virgen de la Concepción aparecida en Carnaxide podía y debía ser adorada. Por ello, las autoridades eclesiástica y política habían convenido trasladarla a la sede de Lisboa, donde se le podría dar un culto más decente que en su cueva. El sermón finalizaba advirtiendo contra los abusos del fanatismo y pidiendo el favor de la Virgen para el sistema constitucional y los progresos que este traería para la nación:

Pedi a Maria santissima alcance pelas suas rogativas a Graça do Espirito Santo para as presentes Cortes, e para a acertada escolha das Cortes futuras. Pedi-lhe que ampare as outras Authoridades Ecclesiasticas e Temporaes, e que em fim

12 Conceição (1823): 221.

13 Loureiro (1939) y Carromeu (2013). 
Deos recebendo benigno os Cultos que a Nação Portugueza hoje consagra a Maria, dê a todo o Reino Unido a Graça do Ceo, a fertilidade da terra, o augmento das Artes, o vigor da Industria, a abundancia do Comercio ${ }^{14}$.

Sin embargo, en mayo de 1823 la experiencia liberal sería truncada por una rebelión que, en un primer momento, tenía al príncipe Miguel como su líder, aunque en seguida fue capitalizada por su padre. El 23 de junio la familia real al completo acudió a la catedral lisbonense para agradecer a la Virgen de la Concepción su protección. Con el retorno al Antiguo Régimen, el uso de esta devoción en los discursos contrarrevolucionarios fue recurrente. En una publicación de 1823 que llevaba el expresivo título de Refutação da Constituição dos Insurgentes podía leerse que la aparición ocurrida el año anterior mostraba «signaes de verdadeiramente prodigioso, ou milagro, na defeza da Religião, e juntamente da monarquia Portugueza». El descubrimiento de la imagen de la Virgen no era un suceso fortuito, sino un hecho providencial para recuperar la alianza del Trono y el Altar en Portugal:

Milagres evidentes forão praticados na invocação á Soberana Virgen Mãi de Deos em sua Imagem Apparecida, consagrada ao mysterio de sua Immaculada Conceição. Pessoas entrevadas pelo espaço de annos de repente recobrárão saude, invocando a Mãi de Deos, diante da sua Imagem Milagrosa. Á vista destes, e outros prodigios continuados a Fé da Religião de Jesu Christo se firmou nos coraçôes dos Portuguezes, e com ella a fidelidade, e sobordinação ao seu Rei, a quan anda sempre unida com o fervor, a desempenho da Religião. O que ama, e respeita a Deos, ama, e respeita o $\operatorname{Rei}^{15}$.

Al mismo tiempo, su identificación con el príncipe se hizo cada vez más evidente $^{16}$. La Inmaculada no solo era la particular defensora de Portugal, sino también la protectora del valiente Miguel, que había liderado el derribo del sistema constitucional. Este uso político se inserta en la génesis del discurso contrarrevolucionario miguelista, que articulaba un conjunto de postulados compartidos por los movimientos absolutistas europeos: la visión pesimista de la naturaleza humana, la negación de la autonomía del hombre y su razón respecto a Dios, la creencia en el orden natural de las cosas, el elogio de la tradición (y, con ella, la legitimación social del Antiguo Régimen) y una visión providencialista de la historia conjugada con un catastrofismo apocalíptico

\footnotetext{
14 Preto (1822): 37.

15 Refutação (1823): 17.

16 Lousada y Ferreira (2006): 33-34 y Ferreira (2014).
} 
que postergaba la salvación redentora tras una pléyade de calamidades como castigo divino a la impiedad del ser humano. $\mathrm{Y}$, en el caso concreto del miguelismo, a todo ello se ańadía la consideración de Portugal como un reino escogido por Dios para la salvación de la humanidad y de Miguel de Braganza como un instrumento de la voluntad divina para tan elevado $\mathrm{fin}^{17}$.

Así pues, el símbolo de la Inmaculada Concepción, que hollaba la serpiente del pecado, era fácilmente identificable con un príncipe Miguel triunfante sobre la Revolución. De esta manera describe los sucesos ocurridos a raíz de la aparición de la Virgen de la Concepción en Portugal Lourenço José Alves en una larga composición poética publicada en 1824. En ella no solo narraba la milagrosa aparición de la Virgen, sino también las "finezas, graças e favores que a Senhora tem feito á Nação Portugueza», según rezaba el título. En este sentido, trazaba una línea de continuidad mesiánica entre el descubrimiento de la imagen de la Virgen y la restauración del trono y el altar. En primer lugar, para legitimar el movimiento contrarrevolucionario, comparaba la aparición de la Virgen en la cueva con el nacimiento de Jesús en Belén, pues ambos eran perseguidos por los regímenes políticos del momento, aunque estuvieran tan alejados temporalmente el uno del otro. De hecho, afirmaba que a los impíos liberales «de Herodes só lhes faltou / dar aos innocentes morte» ${ }^{18}$. Y sobre el sermón del padre Marcos el día de traslado de la imagen, Alves no dejaba de señalar el fin espurio que se encontraba detrás de sus palabras:

Tudo a fim de apoucar pia liberalidade, com que o Povo á Senhora offerta de boa vontade.

Disse, que as Imagens Santas,

Lá segundo o seu pensar,

$\mathrm{Na}$ rua, e frente das cazas

Nunca deverião estar.

Tambem Satanaz não gosta

De as ver em tanta parte;

E se os genios são concordes,

Todos fallão d'igual arte ${ }^{19}$.

17 Lousada (1989); Silva (1993), y Ferreira (2004).

18 Alves (1824): 13.

19 Ibid.: 16. 
El clímax de la composición llegaba en los providenciales sucesos que traerían la libertad al reino: la noche del 27 de mayo de 1823 (en el aniversario en que la Virgen de la Rocha había hecho su aparición) el príncipe Miguel salía de Lisboa y, gracias al patrocinio de María, comenzaba la salvación de Portugal: «Com a graça de Maria, / de São Miguel protecção, / conseguio a liberdade / do reino, e toda a Nação». Desde entonces, la Virgen de la Concepción de la Rocha y el miguelismo estarían íntimamente unidos ${ }^{20}$.

Es difícil considerar esta utilización política de la devoción religiosa en un sentido nacional. Por el contrario, la Inmaculada Concepción seguía siendo para el miguelismo un culto dinástico que ponía de manifiesto la lealtad de los súbditos a la monarquía por medio de una religión que compartían todos los portugueses, y que tenía como un rasgo presuntamente distintivo y propio la creencia en la concepción de la Virgen sin mancha de pecado. Aunque en estos discursos apareciese la palabra nación, el término conservaba todavía su acepción etimológica al denotar una identidad basada en el origen geográfico dentro de los reinos de una monarquía y no un sujeto político soberano. Esta apropiación de términos (también ocurría con el de libertad, como hemos podido comprobar) constituía un recurso de los miguelistas para neutralizar el contenido semántico político del vocabulario liberal y sustituirlo por contenidos propios del Antiguo Régimen revestidos de categorías morales positivas ${ }^{21}$.

Habría que esperar, pues, al establecimiento de un régimen liberal para que la Inmaculada se convirtiese en una devoción de la nación portuguesa. De hecho, fue tras la proclamación dogmática cuando los discursos religiosos que se referían a la Inmaculada en clave nacional se multiplicaron. Además, ello coincidió con la normalización de las relaciones entre la Iglesia y el Estado portugués después de un período abierto por la Revolución liberal que algunos llegaron a caracterizar de "cismático»" ${ }^{22}$. Por entonces, Pío IX había impreso a

20 Prueba de ello es un testimonio recogido en Nossa Senhora (1912): 23. Una vez Luis I (1869-1881) pasó por Carnaxide y preguntó a una anciana del lugar dónde se encontraba la gruta en la que había aparecido la Virgen de la Rocha. La anciana le contestó: «Não vades lá, Senhor Rei, lhe disse a velha, olhos que a vêem tem vontade de chorar; depois que sahiu de Portugal a [sic] sr. D. Miguel perdemos toda esperança de justicia. Sabemos que V. Magestade é bom; mas elle podia mais e queria-nos muito». Estas palabras constituyen un buen ejemplo del llamado «miguelismo popular». Véase Ferreira (2002).

21 Lousada (1989): 120. Compárese con Ferreira (2002: 19), que señala un componente de nacionalismo dentro del miguelismo como elemento moderno de este movimiento.

Doria (2001). 
la Inmaculada un componente reaccionario acorde al reflujo del ciclo revolucionario de 1848.

Ese componente aparece claramente reflejado en un opúsculo aparecido en Lisboa en 1853. Tal y como el título advertía, su anónimo autor disertaba sobre las "congruencias sociales» que implicaría tal proclamación, a saber: una condena en firme a los «errores modernos» por la voz autorizada del sucesor de san Pedro. El asunto de la Inmaculada Concepción no podía ser abordado como un tema de religiosidad popular por los católicos, sino como el «baluarte mais poderozo e opportuno que no prezente tempo se possa oppôr á invasão da heresia mais o menos descuberta $»^{23}$. Toda definición dogmática se hacía contra una herejía, y la de la Inmaculada se opondría a las que se habían desarrollado a partir del protestantismo: el racionalismo, primero teológico, después filosófico y finalmente político. Lutero, filosofismo, Revolución francesa y socialismo eran los cuatro peldaños que conducían a la humanidad a su autodestrucción. La razón había sido deificada, se afirmaba la bondad natural del ser humano y se negaba el pecado original, el hombre se había independizado de Dios y buscaba una nueva redención en las filosofías modernas. Para estas, Cristo no era ningún salvador, sino un mero filósofo cuyas ideas serían tan controvertibles como las de los demás. Y para el autor lo peor de todo era que algunos «semirracionalistas heterodoxos» dentro de la propia Iglesia aceptaban estas ideas y paganizaban el catolicismo. La definición dogmática de la Inmaculada vendría por fin a frenar los envites heréticos de la razón:

Se Maria por singular privilegio foi preservada do peccado original, logo a estirpe de Adão não he pura e santa de origem, mas viciada e culpada e precizada de redempção. Se Maria foi preservada porque Mãe de Deos; logo Christo, seu filho, não he uma idea, mas sim uma pessoa historica e real; não he um filosofo humanitario, mas sim verdadeiro Deos, unindo na simples hypostasis do Verbo eterno a divina á humana natureza. Se Maria foi preservada pelos merecimentos do mesmo Christo reparados da humanidade decaida; logo a missão de Christo não foi terrena e civil, mas celeste e sobrenatural; isto he o resgate do homem do peccado, da morte da alma, da escravidáo de Lucifer: a graça que Christo nos trouxe não foi a civilização politica, mas sim a fé, a vida sobrenatura, a adopçáo de filhos de Deos, a felicidade para a qual por elle fomos destinados, não he a temporaria desta vida, mas a eterna do ceo, e por conseguinte a Igreja não tem missão ou dever de nos fazer felizes terrenamente ${ }^{24}$.

23 Congruencias sociaes (1853): 6.

24 Ibid.: 16-17. 
El dogma de la Inmaculada Concepción de María dejaba claro que el hombre no era bueno por naturaleza. La humanidad estaba corrompida desde que sus primeros padres desoyeron el mandato divino. Si Adán pecó, sus hijos podían volver a pecar; la naturaleza humana no era ni podría ser independiente. Y concluía: «Por isso as maximas da liberdade absoluta, da independencia do pensamento, do reinado da opinão, da soberania humanitaria, são falsas e erradas ${ }^{25}$.

Así, después de 1854 los discursos religiosos vertidos tras la proclamación dogmática en Portugal incorporarían a la dimensión nacional ese componente de enfrentamiento con las ideologías modernas. Los sermones pronunciados a lo largo del país ilustran bien esta amalgama de nación y contrarrevolución. Se celebraba que el papa hubiera definido una creencia particular de la nación portuguesa, como hacía el consejero deán de la sede patriarcal al comenzar su sermón interpelando a los sentimientos nacionales que despertaba la definición dogmática: «Sus portuguezes! Erguei a cabeça com orgulho! ${ }^{26}$. Asimismo, los clérigos afirmaban el patrocinio de la Inmaculada sobre la nación portuguesa, retrotrayendo su existencia hacia atrás en el tiempo y vinculando su libertad con la restauración de la dinastía de los Braganza en tiempos de Juan IV, el mismo rey que había tomado a la Virgen de la Concepción como padroeira ${ }^{27}$. Se trataba, pues, de un discurso que conjugaba a la perfección el componente nacionalista con una dimensión trascendental. Y ello integraba la "nación fidelísima» heredera de la Monarquía dentro de la comunión de todos los católicos en torno a unos valores comunes. Así lo expresaba José Joaquim de Azevedo e Moura, Obispo de Viseu, en su pastoral:

E vós, meus amados filhos, que, com grande satisfação Nossa, tendes dado constantes documentos da vossa piedade e sublime veneração, que tributais à Santíssima Mãe de Deus, sob a invocação de Sua Conceição Imaculada, vós — que pela graça de Deus, e regenerados pelo baptismo, pertenceis ao corpo místico da Igreja Católica, e à Fidelíssima NAÇÃO PORTUGUESA, Padroado da Augusta Rainha dos Anjos sobre aquela gratíssima invocaçâ, e que com tanta especialidade tem sido visívelmente protegida nas situaçōes mais arriscadas, nas públicas calamidades, nos perigos, afliçōes e trabalhos particulares, pela valiosa intercessão de nossa poderosíssima PADROEIRA; vós —-finalmente— que acatais,

\footnotetext{
Ibid.: 17.

Lacerda (1855): 3 .

27 P. ej., la pastoral del arzobispo de Braga, 4-4-1855.Recogida en Pombo (comp.) (1955): 63-64.
} 
submissos e dóceis, as decisóes da Igreja, e prestais pura obediência e firme adesão a seus juízos supremos, pronunciados pela voz autorizada do Vigário de Jesus Cristo, centro luminoso da Unidade Católica- não podeis ficar mudos espectadores, quando a Igreja exulta, quando a Nação Portuguesa, desde o Trono dos nossos Reis até ao mais humilde dos Cidadãos, correm ao Templo a-porfia, endereçando ao Senhor pomposas acções de graças, cânticos, e hinos de louvor, e piadosa devoção à Santíssima Virgem, pela faustíssima nóva que ora vos anunciamos ${ }^{28}$.

Claro está que esos valores que unían a los católicos no eran políticamente asépticos. Los eclesiásticos no dejaron de subrayar el significado doctrinal de la definición dogmática frente a los «errores modernos». José Luís Alves Feijó, gobernador del obispado de Bragança, se admiraba de que la proclamación hubiese llegado «no meio do indiferentismo e do racionalismo do século XIX ${ }^{29}$. Desde una óptica similar, en su sermón en la Iglesia de Santo Domingo de Coimbra, Francisco Antonio Rodríguez de Acevedo predicaba a los fieles que el nuevo dogma preparaba «a conquista pacifica do mundo pela sugeição das intelligencias» ${ }^{30}$. El arzobispo de Évora advertía que no se trataba de un dogma nuevo, sino de un dogma eterno que había sido definido «chegada a época, em que era necessário que a Mãe de Deus aparecesse adornada com todas as feiçóes delineadas pelo Espírito Santo, e que Lhe eram próprias ${ }^{31}$. Desde luego, los sectores políticos más liberales recelaban del uso y abuso que los clérigos pudiesen hacer del nuevo dogma. En este sentido, en una composición poética Antonio Maria Gentil se burlaba de la erudición desplegada por el obispo de Évora al probar el dogma de la Inmaculada Concepción en las fuentes veterotestamentarias:

As correntes do Jordão;

de Holofernes a Judid;

o Abiatar de David;

as graças da Conceição;

a mae Eva; o pae Adão;

28 Pastoral del obispo de Viseu, 30-4-1855. Recogida en Pombo (comp.) (1955): 169. Mayúsculas en el original.

29 Pastoral del gobernador eclesiástico de Braganza, 18-4-1855. Recogida en Pombo (comp.) (1955): 126.

30 Azevedo (1855): 16.

31 Pastoral del arzobispo de Évora, 25-4-1855. Recogida en Pombo (comp.) (1955): 152-153. 
O Embaixador Gabriel;

os leôes de Daniel;

linguas grossas e carnaes;

Babilonia e salgueiraes;

O' que Torre de Babel! ${ }^{32}$

No obstante, el protagonismo fue para los discursos religiosos que celebraban el nuevo dogma. Y si hubo versos que se difundieron, esos fueron los de $O$ triumpho da Igreja Romana na definição da Immaculada Conceição de Maria del jesuita miguelista Carlos João Rademaker, en los que «Os sabios, os filosophos se inclinam» ante la verdad que revelaba el papa y no la razón ${ }^{33}$. Al fin y al cabo, el nacionalismo se conjugaba con una comunión trascendente basada en la pertenencia al cuerpo místico de la Iglesia y la obediencia al papa. Sin que eso fuese óbice para subrayar la singular protección de la Inmaculada, que había pasado de ser patrona de la «monarquía fidelísima» a la de la «nación fidelísima».

\section{DE PATRONA UNIVERSAL DE LOS REINOS DE ESPAÑA E INDIAS A PATRONA DE ESPAÑA}

La Inmaculada Concepción había sido una devoción estrechamente vinculada a la monarquía española desde la Baja Edad Media, pero no fue hasta mediados del siglo Xviı cuando la Corona hizo de la definición dogmática su particular caballo de batalla. En 1652 Felipe IV creó una Junta para conseguir este propósito, que acabó siendo una cuestión de Estado en las relaciones entre Madrid y Roma. El interés de la monarquía católica estribaba en aprovechar la ambigua postura de la Santa Sede, que no terminaba de decidirse ante esta materia teológica, y así intervenir en asuntos eclesiásticos al erigirse en primera potencia católica de la Contrarreforma. Además, la creencia en la singular concepción de María fuera del pecado original legitimaba la acción evangelizadora hispana en América, pues al igual que María había sido preservada de la herencia de Adán y Eva para preparar la venida de Cristo, los indígenas podían romper con el lastre de sus religiones anteriores y abrazar la

\footnotetext{
32 Arquivo Nacional Torre do Tombo, Família Costa Cabral, parte B, cx. 22, m. 16. Estos versos están escritos sobre la propia circular del obispo de Évora en la que daba a conocer la definición dogmática. El autor había subrayado sobre la circular los términos que tomaba para componer la décima.

33 Rademaker (1855): 7.
} 
salvación ${ }^{34}$. No obstante, la Inmaculada no sería «Patrona Universal de los Reinos de España e Indias» hasta 1761, en tiempos de Carlos III. Se trataba de un patronato sobre la monarquía, y no sobre la nación ${ }^{35}$. Y no es casualidad que llegase en un momento en el que periclitaban los fundamentos providencialistas del dominio español sobre América, al tiempo que se imponían las fórmulas imperiales como la de Reino Unido ${ }^{36}$.

Con la guerra de la Convención entre 1793 y 1796 y, sobre todo, la invasión francesa de 1808, se puso de relieve la crisis en la que se encontraba la monarquía española y se abrieron las puertas a nuevas alternativas para solventar esta grave situación. En este sentido, en el devenir político que se desarrolló desde entonces hasta 1814 asistimos a los inicios de la contemporaneidad en España en medio de un proceso bélico inserto en el contexto internacional posterior a la Revolución francesa, y que tiene su correlato interior en una guerra entre patriotas y afrancesados, acompañada por el proceso revolucionario que alumbrará la Constitución de 1812. En ambas dimensiones -bélica y política - el uso de la religión y sus símbolos fue un factor fundamental en el bando patriota para movilizar a la población frente al invasor y garantizar su lealtad en momentos de dificultades e incertidumbres. Desde púlpitos y publicaciones se predicaba una guerra justa incardinada en la historia multisecular de enfrentamiento del bien y el mal, lo trascendente y lo mundano, la Iglesia y sus perseguidores, adobada con un tono apocalíptico que rayaba en lo mesiánico y multitud de referencias veterotestamentales, así como continuas apelaciones a un pasado de la patria - o, ahora cada vez más, la nación-caracterizado por la predilección divina hacia los españoles ${ }^{37}$.

Esta retórica fue ampliamente utilizada por aquellos que vieron tambalearse la monarquía que durante siglos había sido el referente común, junto con la religión, de los súbditos de la monarquía católica. Pero también fue asumida por el temprano liberalismo hispano a la hora de plantear su acción política en aras de la instauración de un régimen constitucional. Lo que buscaban estos primeros liberales era posibilitar el paso de una monarquía a un Estado nacional de manera que las lealtades de los antiguos súbditos

34 Broggio (2013) y Peinado Guzmán (2014). Véase un estado de la cuestión sobre la bibliografía española sobre la Inmaculada Concepción en Martínez Vilches (2017).

35 Como advierte Álvarez Junco (2015): 71, 163. Este autor vincula la declaración del patronato universal al intento de la Corona por acabar con los derechos del cabildo de Santiago de Compostela a cobrar el voto de Santiago.

36 Portillo Valdés (2006).

37 Álvarez Junco (2015); Revuelta (2009); Martínez Ruiz (2010); Barnosell (2010), y Rújula $(2016,2017)$. 
permanecieran intactas entre los nuevos ciudadanos, aunque orientadas a la revolucionaria realidad política que aspiraban a implantar. En este sentido, el catolicismo fue un elemento irrenunciable a la hora de conservar y redirigir los sentimientos de pertenencia de la población española, en tanto que la religión había sido el elemento definitorio de una monarquía cuyo título principal era el de católica y que había tenido como objetivos fundamentales de su actuación en el concierto internacional la defensa del catolicismo en Europa y su extensión en América. Fue así como, en medio de la crisis de esa monarquía católica, el liberalismo español identificó la comunidad de ciudadanos con la comunidad de creyentes, dando a luz una nación católica que heredaba las antiguas lealtades a la religión y las extendía al sistema liberal ${ }^{38}$.

Es por todo ello que el símbolo de la Inmaculada Concepción se utilizó profusamente, tanto por los absolutistas que deseaban derrotar a los franceses para restaurar la alianza del trono y el altar, como por los liberales, cuyos horizontes políticos alumbrarían un sistema constitucional. En primer lugar, en el proceso de formación de juntas se exigió a los integrantes de estas que pronunciaran el juramento de defender la opinión de que María había sido concebida sin mancha de pecado, lo que refleja, más allá de un fenómeno devocional que conjugaba un rasgo de piedad mariana con una identidad colectiva más o menos extendida, la propia lealtad a la monarquía que tanto se había identificado con el patrocinio de la causa inmaculista ${ }^{39}$. Además, el propio contenido de esta creencia sobre la concepción de la Virgen, que remitía directamente a la salvación universal por medio de su hijo, se acomodaba bien a la comprensión de la lucha frente al invasor en términos providenciales. En efecto, al mismo tiempo que el enemigo se identificaba con una fuerza malévola, el conflicto bélico y sus catastróficas consecuencias eran categorizadas como un castigo divino que únicamente cesaría por medio de una voluntad de redención en el bando patriota. Y una de las formas de alcanzar esa redención era, según un despacho dirigido al presidente de la Junta Suprema Central, procurar la definición dogmática de la Inmaculada Concepción:

Serenísimo Señor:

Desengañémonos: mientras no pongamos nuestra confianza en Dios y su Madre no esperemos conseguir victoria de nuestros enemigos. [...] Haga V. A. voto (como ya se lo han aconsejado) a nombre de nuestro amado Rey Fernando

Portillo Valdés (2006, 2007, 2012); Alonso (2014), y Millán y Romeo (2015).

39 Pueden verse los juramentos de las juntas en la prensa patriota de la época. Por ejemplo, en el caso de la del Principado de Cataluña, en Diario de Madrid, 21-81808. 
7. ${ }^{\circ}$ de solicitar la canonización del Misterio de la Concepción de la Virgen. Pues está revelado que ha de llegar tiempo que este dulce Misterio se ha de celebrar en la Iglesia como mysterio de fe: aora $[s i c]$ es el tiempo: pues a un beneficio grande, debe preceder una calamidad y tribulación grande: y quál puede ser mayor ${ }^{30}$

El asunto de la Inmaculada también fue objeto de discusión en las Cortes de Cádiz. A la hora de establecer los términos del juramento ante las Cortes que el monarca habría de pronunciar llegado el día de su advenimiento al trono, el diputado guatemalteco Antonio de Larrazábal, clérigo liberal, propuso, entre otras adiciones, que en el texto del juramento se incluyese la defensa de la creencia en la Inmaculada Concepción. Larrazábal exponía la profunda raigambre que tenía "la devoción española» de la Inmaculada en la historia de la monarquía como su particular protectora. Por ello, consideraba que «en la constitución fundamental de la monarquía, que ahora establece la nación, congregada en las Cortes generales y extraordinarias las más solemnes que se han visto, es muy debido se coloque esta fórmula de juramento en obsequio de su patrona y protectora». Terció entonces en el debate Argüelles, subrayando que el rey ya juraba defender y conservar la religión católica, por lo que juzgaba innecesario hacer mención al misterio de la Inmaculada. Además, si esta era patrona de España, también lo era Santiago, y habría que hacer una mención también al santo compostelano. Pero Larrazábal insistía en la necesidad de ampliar el juramento, y en lo conveniente que era en el contexto de la resistencia frente a los ejércitos napoleónicos: «Señor, mi principal intento es que toda la nación entienda que confiando V. M. el salvamento de la patria al patrocinio de la gran madre de Dios, se interesan las Cortes en promover las glorias del misterio de su Concepción, que aunque no es de fe, ha llegado al estado de próxima definibilidad en que con gozo universal le vemos por nuestra dicha» ${ }^{41}$.

No obstante, el verdadero uso como símbolo nacional de la Inmaculada Concepción en España habría de esperar a la proclamación dogmática de este misterio, en diciembre de 1854. Con el regreso de la alianza del trono y el altar con Fernando VII, y el intento de perpetuar esa situación por su hermano Carlos de Borbón, los liberales vieron el peligro del uso de las devociones populares, especialmente las marianas, por parte de poderes públicos dispuestos a movilizar a la población frente a cualquier tipo de reforma. No en vano, Antonio Alcalá Galiano censuraba el nombramiento de la Virgen de

40 Archivo Histórico Nacional, Estado, leg. 52-H, exp. 410. Anónimo sin fecha.

41 Esta cita y las anteriores en Diario de Sesiones, n.o 379, 16-10-1811. 
los Dolores como Generalísima de las tropas carlistas como un «linaje de devoción impertinente que casi rozaba con la impiedad». Y en un sentido similar, Antonio Pirala calificaba ese nombramiento como "prueba oficial de fanatismo». Ambos sabían que no hacía tanto tiempo que los españoles habían invocado a la Virgen y a los santos para hacer frente a los franceses, pero su valoración moral de uno y otro uso de lo religioso estribaba en los distintos objetivos que se perseguían, así como en el tiempo transcurrido desde entonces $^{42}$. Y no mucho tiempo después, Ildefonso Bermejo aduciría otra razón, no menos grave en un momento en el que se imponía la religiosidad emotiva propia de la cultura burguesa: «No era lícito, no era prudente, no era cristiano poner a la cabeza de tantos desastres a la que dio ejemplos de ternura y mansedumbre» ${ }^{43}$.

Sin embargo, no fue solo la definición como artículo de fe lo que incitó al uso nacionalizador de esta advocación, sino también, y muy particularmente, el contexto de desavenencias entre la Iglesia y el Estado debido a la nueva situación política abierta por el Bienio Progresista, en el que el debate de una nueva constitución amenazaba la exclusividad del culto católico en el país. Con las posiciones polarizadas, la bula de la definición dogmática de la Inmaculada vino a generar más tensiones en torno a la religión en España ${ }^{44}$.

Ya las noticias del advenimiento de la definición dogmática levantaban recelos entre el liberalismo progresista, que asistía expectante a lo que consideraba - y en realidad así era - una deriva de fortalecimiento del poder papal en un sentido reaccionario y ultramontano. Por esto, y ante la encíclica pontificia del 1 de agosto de 1854 convocando a los obispos a las conferencias previas a la proclamación dogmática, un artículo en el periódico progresista La Iberia recordaba al Gobierno «su sagrado deber de protector de los cánones» ante "tamaño abuso", "para que no recaiga tanta mengua sobre una nación que siempre ha blasonado de católica ${ }^{45}$. La polémica no respondía solo a la pretensión de Pío IX de proclamar un nuevo dogma de fe fuera de un concilio. Las suspicacias de los liberales se debían también a la posibilidad de que la definición dogmática viniese acompañada de algún anatema político más o menos explícito. Y ante ello cabía el recurso de negar el regio exequatur a la

42 Alcalá Galiano (1844-1846): VII, 377 y Pirala (1865): I, 298.

43 Bermejo (1871-1872): I, 236.

44 Kiernan (1970) y Núñez y Muñoz y Díaz de Cerio (1993).

45 La Iberia, 17-11-1854. El debate siguió tras la definición dogmática y acabaron imponiéndose los autores inmaculistas, que reconocían la licitud del procedimiento de Pío IX al respecto. Véase Mínguez Blasco (2014). 
bula, como finalmente sucedió. No sería hasta el 9 de mayo de 1855 cuando una real orden permitiese su publicación ${ }^{46}$.

Los sermones realizados con motivo de la definición dogmática también conjugaban en Espańa el componente nacional con el elemento contrarrevolucionario, la unidad nacional con la comunión trascendente del orbe católico. Así, desde el púlpito de Santa María del Mar en Barcelona el franciscano exclaustrado Ramón Buldú, «amante como el que más de las glorias de nuestra patria", afirmaba ante su auditorio la vinculación entre el nuevo dogma y los españoles, quienes "como hijos primogénitos de María» habían sido los primeros en defenderlo. Ahora, Pío IX les daba la razón con su autorizada e infalible voz como depositario de las esencias de la religión. Una voz que acudía como un bálsamo ante una «enfermedad» que sufría el siglo: el exceso de confianza de los hombres en «sus propias luces», la exaltación del «imperio de la razón sobre todo imperio", la insumisión ante cualquier autoridad ${ }^{47}$. Para el franciscano, la soberanía de la razón llevaba a la soberanía de la voluntad y, con ella, la desobediencia generalizada y la disolución social. El dogma de la Inmaculada venía a curar esa enfermedad recordando que solo María tenía la gracia de no estar corrompida, mientras que el resto del género humano, sin la ayuda de la religión, estaba orientado hacia el pecado. De ahí la proliferación de los «errores modernos» en la época, que la Inmaculada Concepción venía a conjurar:

Siglo XIX, tu ambición, tu pasión consiste en alcanzar la unidad; ¿̇ónde te será dado encontrarla? ¿Quién te la proporcionará? ¿¿Acaso esas numerosas sectas que han querido dirigir tu marcha? Pero reflexiona qué es lo que han hecho para procurártela todas ellas. ¿Qué han hecho en favor de la unión los sistemas sensualistas? ¿Qué la escuela racionalista? ¿Qué la filosofía escocesa? ¿Qué el kantismo? ¿Qué el fatalismo? ¿Qué los sansimonianos con su amor reciproco entre los hombres? ¿Qué Fourier con su atracción apasionada? ¿Qué Owen con sus sociedades cooperativas? ¿Qué tantos otros sistemas que te prometían la unión, y con ella la felicidad? Nada, absolutamente nada han hecho para proporcionártela;

46 Y ello con notables prevenciones, según se puede leer en la Real Orden: «S. M. la Reina [...] se ha servido dar el Pase en la forma ordinaria a la Bula Ineffabilis Deus [...] entendiéndose que es sin perjuicio de las leyes, reglamentos y disposiciones que organizan en la actualidad o arreglen en lo sucesivo el ejercicio de la libertad de imprenta y la enseñanza pública y privada, de las demás leyes del Estado, de las regalías de la Corona, y de las libertades de la Iglesia espańola». La Real Orden de 9-5-1855 se recoge en Colección legislativa de España. Tomo LXV (1855): LXV, n. 277.

47 Buldú (1855): 4, 7. 
digo mal [sic: más], ellos trabajaron para hacerla imposible. Sin embargo no te será difícil encontrarla. Escucha lo que van repitiendo todos los príncipes de la Iglesia, todos los obispos del orbe católico, todos los ministros del altar, todas las vírgenes consagradas a Dios, y más de doscientos millones de fieles: Creo que la Beatísima Virgen María fue preservada del pecado original ${ }^{48}$.

Esa unidad en torno a la Inmaculada y en torno al catolicismo también se podía verificar a escala nacional. España, «nación católica por antonomasia», no debía olvidar su próspero pasado, fruto de la identificación sin fisuras entre los españoles y el catolicismo. Y esa unidad se patentizaba, según Buldú, en la antigua y firme creencia de los españoles en la Inmaculada, pues «sinónimos han sido hasta ahora las voces español y defensor de la gracia original de María» ${ }^{49}$. Y en los mismos términos se pronunciaba Manuel Muñoz y Garnica, canónigo de la catedral de Jaén y predicador de S. M., el 22 de septiembre de 1855 en la seo jienense: "Ningún pueblo nos ganó por la mano en tributar a la Inmaculada Concepción de la Santísima Virgen el culto que llevamos a otras partes» ${ }^{50}$. En cambio, al otro lado del Atlántico, el arzobispo de Santiago de Cuba, Antonio María Claret, pasaba por alto la vinculación entre los españoles y el misterio mariano que la Santa Sede había elevado a dogma de fe, y prefería detenerse a explicar la irritación de los «malos» ante la definición, "porque Satanás sugería a los hombres la libertad de examen, de conciencia, del individuo y, finalmente, el protestar contra todo orden, toda ley, todo derecho y toda moralidad $»^{51}$.

Las obras de los publicistas católicos recogían el mismo tono que los sermones. El prolífico Joaquín Roca y Cornet señalaba que el dogma venía a declarar «viciada y desnuda toda la naturaleza humana, la necesidad de una reparación, la odiosa existencia de una culpa de origen que imposibilita al hombre gobernarse y satisfacerse por sí solo» ${ }^{52}$. Por ello, Dios había dispuesto que fuese en el siglo xIx, y no antes, cuando la verdad del dogma se proclamase, "para que el siglo más horriblemente sacudido por el error y por la impiedad, tuviese lugar a la palabra consoladora e infalible que añadiendo a la gran Madre de Dios este tributo de gloria, la impulsase, por decirlo así, de nuevo para salvar

\footnotetext{
48 Buldú (1855): 13.

49 Ibid.: 14.

50 Muñoz y Garnica (1856): 251.

51 Claret (1856): 24. Sobre el ideario contrarrevolucionario del arzobispo Claret, que tendría mucho que ver en su posterior labor como confesor de Isabel II, véase Martínez Vilches (2018).

52 Roca y Cornet (1856): 15.
} 
la desvalida humanidad $»^{53}$. Asimismo, el autor se ufanaba en afirmar que "puede España gloriarse de haber sido la primera en honrar a María bajo el misterio de la inmunidad original», y para ello aportaba como pruebas históricas el breviario de san Isidoro aprobado en el IV Concilio de Toledo (633) y la doctrina de san Ildefonso sobre la Virgen María ${ }^{54}$. Y advertía «que nuestra verdadera nacionalidad que se apoya en el Catolicismo se halla como vinculada en el reconocimiento y amor de este dulcísimo misterio de María ${ }^{55}$. Y, en fin, en un mismo sentido prologaba Basilio Sebastián Castellanos de Losada su Reseña histórica acerca de los fundamentos, devoción, controversia y festividad de la Inmaculada Concepción de María Santísima con una dedicatoria al papa en la que mezclaba su condición de español con la de católico:

[El libro] Está escrito con la entera voluntad de un alma creyente, y de un español entusiasta de las glorias de su patria, de la que es la mayor la santísima Virgen nuestra divina Patrona, que se dignó asistirnos con su gracia, visitándonos en cuerpo y alma antes de su dichoso tránsito, para imponernos el deber de amarla como su pueblo escogido, al señalar al Apóstol Santiago la dedicación del templo de Zaragoza, que fue el primero de la cristiandad que se levantó en honor suyo ${ }^{56}$.

En suma, en España la lectura en clave nacional del nuevo dogma recogía el componente contrarrevolucionario que sobre él había proyectado Pío IX. Además, la identificación entre nación y religión por medio de la Inmaculada venía a rebatir aquellas posturas que en los debates constitucionales del Bienio Progresista abogaban por la tolerancia religiosa. Todo ello permearía después en la concepción integrista y excluyente de lo que sería el nacionalcatolicismo ${ }^{57}$.

\section{CONCLUSIONES}

A la luz del recorrido hecho hasta aquí, podemos afirmar que el uso nacional y político de la Inmaculada Concepción como patrona de Portugal

\footnotetext{
53 Roca y Cornet (1856): 20.

54 Ibid.: 22. Confundía en el primer caso el breviario original del arzobispo hispalense con el que editó siglos después Cisneros. Respecto a san Ildefonso de Toledo, el llamado Capellán de María, defendió su maternidad virginal, no su concepción inmaculada.

55 Roca y Cornet (1856): 65-66.

56 Castellanos de Losada (1855): s. p. No es casual que hiciese mención a la Virgen del Pilar, pues por entonces la advocación zaragozana se estaba cargando de contenidos nacionalistas. Véase Ramón Solans (2014).

57 Mínguez Blasco (2014).
} 
y España fue paralelo en los dos países ibéricos. Ambos partían de un pasado de devoción mariana estrechamente vinculada a la identidad de sus respectivas monarquías, pero el patronazgo de la Inmaculada llegaría en momentos críticos para las mismas como elemento de legitimación: en Portugal durante la lucha por la restauración de la dinastía de los Braganza en el trono a mediados en el siglo XVII, y en España ante los primeros síntomas de crisis de la monarquía atlántica en la segunda mitad del siglo xviri. En ambos casos, se trataba de una devoción dinástica que expresaba el conjunto de lealtades del Antiguo Régimen que vinculaban a los súbditos con la monarquía, utilizando para ello un elemento de referencia como el de la religión. Con la crisis del Antiguo Régimen, ese uso político se intensificó, como han puesto de relieve los ejemplos de la guerra de la Independencia en el caso español y el miguelismo en el caso portugués. Si bien es cierto que en esos momentos comienza a utilizarse el término nación para hacer mención a la comunidad que era objeto del favor singular de la Virgen, es difícil atribuir a esta palabra la denotación de un sujeto colectivo con vocación política. Así, no fue hasta la imposición del liberalismo cuando los discursos religiosos asumieron el componente nacional, como ponen de manifiesto tras la proclamación dogmática de 1854. Para entonces, junto con esa dimensión nacional, la Inmaculada Concepción estaría cargada de connotaciones contrarrevolucionarias que los eclesiásticos y los autores católicos también se encargaron de transmitir a la población.

La nacionalización y politización de una devoción dinástica que acabó convertida en devoción nacional nos pone sobre la pista de un proceso paralelo en Espańa y Portugal, pero que también sería preciso indagar en otros países católicos. Se trata del paso de monarquía a nación a través del componente religioso: en España, de monarquía católica a nación católica; en Portugal, de monarquía fidelisima a nación fidelísima. Y no parece que la importancia de la religión en este paso estribase en la correlación de fuerzas en el momento de la caída del Antiguo Régimen, que supuestamente hubiese impedido un pleno desarrollo del liberalismo. Muy al contrario, este fenómeno exige una óptica que calibre el factor religioso como elemento de continuación y de atribución de las antiguas lealtades del Antiguo Régimen a las realidades políticas abiertas por el liberalismo, así como un análisis de su funcionalidad política en ese nuevo contexto. En fin, podemos afirmar que liberalismo y catolicismo se impregnaron mutuamente a la hora de plantear la construcción de la nación, aunque desde presupuestos distintos. Y es en esta contradicción donde puede explorarse la confrontación entre ambos, no en términos de secularización frente a clericalismo, sino de distintos intereses que pretendían la instrumentación de lo religioso en su favor. 


\section{Bibliografía}

Alcalá Galiano, A. (1844-1846). Historia de España desde los tiempos primitivos hasta la mayoría de la reina Doña Isabel II (vol. 7). Madrid: Sociedad Literaria y Tipográfica.

Alonso, G. (2014). La nación en capilla. Ciudadanía católica y cuestión religiosa en España (1793-1874). Granada: Comares.

Álvarez Junco, J. (2015). Mater Dolorosa. La idea de España en el siglo XIX. Barcelona: Taurus.

Alves, L. J. (1824). Novo cantico historico da aparição de nossa Senhora da Conceição da Rocha, expressivo das finezas, graças, e favores que a Senhora tem feito á Nação Portugueza. Lisboa: R. J. Carvalho.

Angelier, F. y Langlois C. (eds.) (2000). La Salette. Apocalypse, pélerinage et literature (18461996). Grenoble: Jérôme Million.

Azevedo, F. A. R. de (1855). Sermão em acção de graças pela definição dogmatica da Immaculada Conceição de Nossa Senhora. Lisboa: J. P. M. Lavado.

Barnosell, G. (2010). La guerra de la Independencia como guerra religiosa: el ejemplo de los sitios de Zaragoza y Gerona. Nuevo Mundo Mundos Nuevos, 10. Disponible en: https:// doi.org/10.4000/nuevomundo.59671.

Bermejo, I. (1871-1872). La estafeta de Palacio: historia del último reinado (vol. 1). Madrid: R. Labajos.

Béthouart, B. y Lottin, A. (eds.) (2005). La devotion mariale de l'an mil à nos jours. Arras: Artois Presse Universitaire.

Blackbourn, D. (1993). Marpingen. Apparitions of the Virgin Mary in Bismarckian Germany. Oxford: Clarendon Press.

Boyd, C. P. (2007). Paisajes míticos y la construcción de las identidades regionales y nacionales: el caso del santuario de Covadonga. En C. P. Boyd (ed.). Religión y politica en la España contemporánea (pp. 271-294). Madrid: Centro de Estudios Políticos y Constitucionales.

Broers, M. (2002). The Politics of Religion in Napoleonic Italy. The War against God, 18011804. London: Routledge. Disponible en: https://doi.org/10.1093/ehr/117.474.1279.

Broggio, P. (2013). Teologia, ordini religiosi e rapporti politici: la questione dell'Immacolata Concezione di Maria tra Roma e Madrid (1614-1663). Lusitania Sacra, 65 (extra 1), 255-281. Disponible en: https://doi.org/10.3989/hs.2013.022.

Buldú, R. (1855). Sermón con motivo de la definición dogmática de la Inmaculada Concepción. Barcelona: Pons y C. a.

Carromeu, F. (2013). Arcebispo e maçon: o padre Marcos na reforma liberal do Estado e da Igreja (1830-51). Lisboa: Colibri.

Castellanos de Losada, B. S. (1855). Reseña histórica acerca de los fundamentos, devoción, controversia y festividad de la Inmaculada Concepción de María Santísima. Madrid: D. J. M. Alonso.

Cattanneo, M. (1995). Gli occhi di Maria sulla Rivoluzione. "Miracoli» a Roma e nello stato della chiesa (1896-1797). Roma: Istituto Nazionale di Studi Romani.

Cecchin, S. (2004). Texto y contexto de la definición dogmática de la Inmaculada Concepción. Carthaginensia: Revista de Estudios e Investigación, 20 (37-38), 1-34. 
Claret, A. M. (1856). Carta pastoral con motivo de haberse declarado dogma de fe el misterio de la Inmaculada Concepción de la Santísima Virgen María. Barcelona: Herederos de la Viuda de Pla.

Colección legislativa de España. Tomo LXV (1855). Madrid: Imprenta Nacional.

Conceição, C. de (1823). Gabinete historico. Tomo IX. Lisboa: Imprensa Nacional.

Congruencias Sociaes (1853). Congruencias sociaes de uma definição dogmatica sobre a Immaculada Conceição da Santissima Virgem Maria. Lisboa: A. J. de Paula.

Coreth, A. (2004). Pietas Austriaca. West Lafayette: Purdue University Press.

Costa, A. de J. da (1957). A Virgem, Padroeira de Portugal na Idade Média. Lusitania Sacra, 2, 7-49.

Di Stefano, R. y Ramón Solans, F. J. (eds.) (2016). Marian Devotions, Political Mobilization and Nationalism in Europe and America. London: Palgrave-Macmillan. Disponible en: https://doi.org/10.1007/978-3-319-43443-8.

Doria, L. (2001). Do cisma ao convénio. Estado e Igreja de 1831 a 1848. Lisboa: Imprensa de Ciências Sociais.

Faria, A. M. (2006). Os liberais na estrada de Damasco: clero, Igreja e religiāo numa conjuntura revolucionária (1820-1823). Lisboa: Fundação Calouste Gulbenkian; Fundação para a Ciência e Tecnologia.

Faria, F. L. de (1984). Crença e culto da Imaculada Conceição em Portugal. Revista Española de Teología, 44 (1), 137-160.

Faria, J. A. de A. (2010). A Restauração prodigiosa de Portugal, 1640-1668. Serpédica: Universidade Federal Rural do Rio de Janeiro.

Fattorini, E. (dir.) (1997). Santi, culti, simboli nell'età della secolarizzacione (1815-1915). Roma: Sossenberg and Sellier.

Fernandes, M. B. L. (1865). Memoria das medalhas e condecoraçóes portuguezas, e das estrangeiras com relação a Portugal. Memorias da Academia Real das Sciencias de Lisboa. Classe de Sciencias Moraes, Politicas e Bellas-Lettras, 3 (2), paginación independiente.

Ferreira, M. de F. S. e M. (2002). Rebeldes e insubmissos. Resistências populares ao liberalismo (1834-1844). Oporto: Ediçóes Afrontamento.

(2004). «Vencidos, pero no convencidos»: movilización, acción colectiva e identidad en el miguelismo. Historia Social, 49, 73-96.

(2014). Nuestra Señora de Rocha de Carnaxide: una devoción por el miguelismo. En R. Serrano García, Á. de Prado Moura y E. Larriba (eds.). Discursos y devociones religiosas en la Peninsula Ibérica, 1780-1860. De la crisis del Antiguo Régimen a la consolidación del Liberalismo (pp. 151-162). Valladolid: Universidad de Valladolid.

Harris, R. (1999). Lourdes. Body and Spirit in the Secular Age. London: Penguin Books.

Haupt, H. G. (2008). Religião e nação na Europa no século xıx: algumas notas comparativas. Estudos Avançados, 22 (62), 77-94. Disponible en: https://doi.org/10.1590/ S0103-40142008000100006.

Haupt, H. G. y Langewiesche, D. (eds.) (2001). Nation und Religion in der deutschen Geschichte. New York: Campus Frankfurt.

(2010). Nación y religión en Europa. Sociedades multiconfesionales en los siglos XIX y XX. Zaragoza: Cometa. 
Jonas, R. (2000). France and the Cult of the Sacred Heart. An Epic Tale for Modern Times. Los Ángeles: University of California Press. Disponible en: https://doi.org/10.1525/california/9780520221369.001.0001.

Kaufman, S. K. (2005). Consuming Visions. Mass Culture and the Lourdes Shrine. Ithaca: Cornell University Press.

Kiernan, V. G. (1970). La Revolución de 1854 en España. Madrid: Aguilar.

Kselman, Th. (1983). Miracles and Prophecies in Nineteenth-Century France. New Jersey: Rutgers University Press.

Lacerda, J. M. d'A. e A. C. de (1855). Sermão em acção de graças pela definição dogmatica da Immaculada Conceição de Nossa Senhora. Lisboa: Silva.

Langlois, C. (2005). Le temps de l'Immaculée Conception. Définition dogmatique (1854) et événement stucturant. En B. Béthouart y A. Lottin (eds.). La devotion mariale de l'an mil à nos jours (pp. 366-379). Arras: Artois Presse Universitaire.

Loureiro, C. H. G. de (1939). O padre Marcos e o liberalismo: seu papel na reforma eclesiástica. Porto: Empresa de Publicidade do Sul.

Lousada, M. A. (1989). O Miguelismo, um discurso contrarevolucionári. En Do Antigo Regime ao liberalismo, 1850-1850 (pp. 112-121). Lisboa: Vega.

Lousada, M. A. y Ferreira, M. de F. S. e M. (2006). D. Miguel. Lisboa: Círculo de Leitores.

Martínez Ruiz, E. (2010). La Iglesia española contra Napoleón: la guerra ideológica. Madrid: Actas.

Martínez Vilches, D. (2017). La Inmaculada Concepción en España. Un estado de la cuestión. 'Ilu. Revista de Ciencias de las Religiones, 22, 493-507. Disponible en: https://doi. org/10.5209/ILUR.57426.

(2018). Antonio María Claret y el confesor real en el régimen liberal (1857-1868). En

R. Sánchez y D. San Narciso (eds.). La cuestión de Palacio: corte y cortesanos en la España contemporánea (pp. 243-261). Granada: Comares.

- (2019). La Corona y sus fervores. Las devociones religiosas de la familia real durante el reinado de Isabel II. En R. Sánchez (coord.). Un rey para la nación. Monarquía y nacionalización en el siglo XIX (pp. 77-103). Madrid: Sílex.

(2020a). The Pious Crown: The Monarchy's Religious Devotions during the Reign of Isabel II. En D. San Narciso, M. Barral y C. Armenteros (eds.). Monarchy and Liberalism in Spain: The Building of the Nation-State, 1780-1931 (pp. 169-183). Abingdon, Oxon: Routledge. Disponible en: https://doi.org/10.4324/9780367810375-9.

- (2020b). Sine labe concepta. La proyección de un modelo de feminidad católica a través de la Inmaculada Concepción en la España del siglo xix. Arenal: Revista de Historia de las Mujeres, 27 (2), 495-518. Disponible en: https://doi.org/10.30827/ arenal.v27i2.6769.

Menozzi, D. (2014). Contro la modernità politica: l'Immacolata Concezione di Maria. Politica e Religione. Annuario di Teologia Politica, 149-176.

Millán, J. y Romeo, M. C. (2015). La nación católica en el liberalismo. Las perspectivas sobre la unidad religiosa en la España liberal, 1808-1868. Historia y Politica, 34, 183-209. Disponible en: https://doi.org/10.18042/hp.34.07.

Mínguez Blasco, R. (2014). Las múltiples caras de la Inmaculada: religión, género y nación en su proclamación dogmática (1854). Ayer, 96, 39-60. 
Mínguez Blasco, R. (2016). Evas, Marías y Magdalenas. Género y modernidad católica en la España liberal (1833-1874). Madrid: Centro de Estudios Políticos y Constitucionales.

Muñoz y Garnica, M. (1856). Sermones. Madrid: A. G. de la Librería Española y Extranjera.

Nossa Senhora (1912). Nossa Senhora da Conceição da Rocha de Carnaxide. Lisboa: Viuva Macieira e Filhos.

Núñez y Muñoz, M. F. y Díaz de Cerio, F. (1993). El Bienio Progresista (1854-1856) y la ruptura de relaciones de Roma con España según los documentos vaticanos. Madrid: Universidad de La Laguna.

Peinado Guzmán, J. A. (2014). La Monarquía española y el dogma de la Inmaculada Concepción: fervor, diplomacia y gestiones a favor de su proclamación en la Edad Moderna. Chronica Nova, 40, 247-276.

Pirala, A. (1865). Historia de la Guerra Civil, y de los partidos liberal y carlista (vol. 2). Madrid: Mellado.

Pombo, M. R. (comp.) (1955). Mariologia Portuguesa (subsidios) (vol. 1). Lisboa: s. n.

Portillo Valdés, J. M. (2012). La crisis imperial de la Monarquía Española. Historia y Espacio, 39, 160-177.

(2006). Crisis atlántica. Autonomía e independencia en la crisis de la Monarquia Hispana. Madrid: Marcial Pons; Fundación Carolina.

- (2007). De la Monarquía Católica a la nación de los católicos. Historia y Política, 17, 17-35.

Preto, M. (1822). Sermão prégado na trasladação solemnissima, que as Authoridades Seculares e Ecclesiastica fizerão no dia 5 de Agoto do presente ano da Imagem de N. S. da Conceição. Lisboa: M. P. de Lacerda.

Rademaker, C. J. (1855). O triumpho da Igreja Romana na definição da Immaculada Cnceição de Maria. Lisboa: Imprensa Nacional.

Ramón Solans, F. J. (2014). "La Virgen del Pilar dice...»: usos políticos y nacionales de un culto mariano en la España contemporánea. Zaragoza: Prensas de la Universidad de Zaragoza.

Refutação (1823). Refutação da Constuição dos Insurgentes. Lisboa: Simão Thaddeo Ferreira.

Revuelta, M. (2009). El sentido religioso de la Guerra de la Independencia. En J. M. Magaz Fernández (ed.). La Iglesia en los orígenes de la España contemporánea (pp. 207-281). Madrid: Facultad de Teología San Dámaso.

Roca y Cornet, J. (1856). María Inmaculada. Recuerdos históricos y afectuosos desahogos. Barcelona: José Ribet.

Rodriguez, M. (1998). Du voeu royal au voeu national. Les Cahiers du Centre de Recherches Historiques, 21, 53-74. Disponible en: https://doi.org/10.4000/ccrh.2513.

Rújula, P. (2016). El nacimiento de un patriotismo monárquico. En E. y C. García Monerris y I. Franquet (eds.). Cuando todo era posible: liberalismo y antiliberalismo en España e Hispanoamérica (1780-1842). Madrid: Sílex.

- (2017). El desafío de la revolución en España. En P. Rújula y F. J. Ramón Solans (eds.). El desafio de la revolución: reaccionarios, antiliberales y contrarrevolucionarios (siglos XVIII y XIX) (pp. 13-27). Granada: Comares.

Serrano, R., Prado, Á. de y Larriba, E. (eds.) (2014). Discursos y devociones religiosas en la Peninsula Ibérica, 1780-1860. De la crisis del Antiguo Régimen a la consolidación del liberalismo. Valladolid: Universidad de Valladolid. 
Serrano, R., Prado, Á. de y Larriba, E. (eds.) (2018). Dimensiones religiosas de la Europa del Sur (1800-1875). Valladolid: Universidad de Valladolid.

Silva, A. B. M. da (1993). Miguelismo: ideologia e mito. Coimbra: Minerva.

Zimdars-Swartz, S. L. (1992). Encountering Mary. Visions of Mary from La Salette to Medjugorje. New York: Princeton University Press. Disponible en: https://doi.org/10.1515/ 9781400861637. 